Seán Ó Riordáin - File faoi sceimhle?

Author(s): Liam Mac Amhlaigh

Source: Comhar, Iml. 66, Uimh 11 (Nov., 2006), pp. 27-28

Published by: Comhar Teoranta

Stable URL: https://www.jstor.org/stable/25575564

Accessed: 16-07-2019 09:21 UTC

JSTOR is a not-for-profit service that helps scholars, researchers, and students discover, use, and build upon a wide range of content in a trusted digital archive. We use information technology and tools to increase productivity and facilitate new forms of scholarship. For more information about JSTOR, please contact support@jstor.org.

Your use of the JSTOR archive indicates your acceptance of the Terms \& Conditions of Use, available at https://about.jstor.org/terms

Comhar Teoranta is collaborating with JSTOR to digitize, preserve and extend access to Comhar 


\section{Seán Ó Riordáin - File faoi sceimhle?}

\section{Liam Mac Amhlaigh}

Is deacair a mheas cé chomh cráite is a bhí Seán Ó Ríordáin le linn dó a chuid filíochta a scríobh. Ní féidir a shéanadh go raibh coimhlintí faoi leith i rith a shaoil a chruthaigh mórbhuairt dó, go fisiciúil ar thaobh amháin agus go hintleachtúil ar thaobh eile.

Ag an am céanna, d'fhéadfá a mheas gurbh iad na coimhlintí a bhí mar spreagadh aige, a chuir iachaill air, cuid dá fhilíocht ba láidre is ba smaointiúla a chruthú. Ag pointí ar leith luaitear an Eaglais Chaitliceach, creideamh i nDia, an eitinn agus deacrachtaí teanga mar fhadhbanna ina shaol mar aon leis an gcineál drogaill a bhí air meascadh go cuimsitheach leis an gcuid eile den ghnáthshaol.

B'iad siúd na nithe a mhúnlaigh an sort beatha a bhí aige, a chuir faoi bhrú é ach a ghríosaigh é chun ardchaighdeán filíochta a chur le chéile.

Ceann na buanna ba threise a bhí ag an Ríordánach ná an cumas a bhí aige na téamaí ba shoiléire a tháinig trasna ina chuid filíochta a nascadh le chéile, a chur i gcomparáid le chéile agus go deimhin codarsnacht a dhéanamh eatarthu.

Bhí ceisteanna ina aigne aige faoina chumas scríbhneoireachta - an file a bhí ann ar an gcéad dul síos? Bhí an bhuairt chéanna air nach scríbhneoir a bhí ann go fíreannach is a bhí aige nach ball den chine daonna a bhí ann uaireanta. Is é sin le rá, nach raibh sé in ann meascadh i gceart lena chomhshaoránaigh nó sa tslí chéanna nach raibh sé in ann fílíocht a chumadh go nádúrtha. Tugann sé le fios sa dán 'Saoirse' go bhfuil sé scoite amach uaidh féin agus cé go mb’fhéidir go bhfuil sé éasca a cheapadh go dtugann an $\mathrm{t}$-aonarachas sin cead (saoirse) dó filíocht a scríobh, i ndáirire, ní cheadaíonn an spás seo ach uaigneas. Mar sin, bíonn amhras aige faoina cheird seachas aon rud eile.

'Raghaidh mé síos i measc na ndaoine... raghaidh mé síos ag lorg daoirse ón mbinibshaoirse ${ }^{i}$ '

Ceann de na fáthanna a bhraith sé faoi chois ina cheann féin i leith cúrsaí scríbh ná de dheasca na
Gaeilge. Is é sin le rá, toisc nach raibh an Ghaeilge aigesean chomh híon is a bhí ag roinnt eile, mar a cheap sé.

Ba as ceantar breacghaeltachta Baile Bhúirne an Riordánach (ba mar bhreacghaeltacht a bhreathnaigh seisean uirthi) agus d'imigh sé go cathair Chorcaí ina dhiaidh sin. Rinne sé cúirt a thabhairt ar Chorca Dhuibhne ina dhiaidh, áit inar 'mheasc' sé le pobal iomlán Gaeltachta, dar leis.

Chinntigh sé uaidh sin ina aigne nach raibh Gaeilge den scoth aige go comparáideach. Ní dóigh liom gur thuig sé mar sin cár sheas sé ina aigne féin i leith na Gaeilge ós rud nach raibh a chuid Gaeilge maith go leor ina thuairim féin.

'An teanga bhocht thabhartha gan sloinne tú, a theanga? ii' Cúis buartha a bhí ann dó, rud a chráigh é gan amhras: go príomhdha, nach raibh an Ghaeilge aige maith go leor chun fílíocht shubstaintiúil a scríobh ach chomh maith le sin go raibh sé ag caitheamh drochmheasa air féin toisc an teanga a bhí in usáid aige.

'Do d'iompar atáimse, do mhalairt im chluasaibh, ag súrac atáirse ón Stríopach allúrach ${ }^{\text {iii }}$,

Ní raibh ach réiteach amháin ar an scéal seo, an taon leigheas ar shuíomh na drochghaeilge, nó Gaeilge atá ídithe faoi smacht an Bhéarla, is é sin, do chorp is d'intinn go léir a thabhairt don teanga.

'Ní mór dúinn dul in aice leat go sloigfi sinn ionat iv'; 'caithfeam dul ionat ${ }^{v}$ ',

Tá an nascadh cumasach de théamaí ríshoiléir nuair a smaoinítear faoi na línte sin thuas. Bhí an tinneas coirp a bhí aige leath ina aigne aige nuair a luann sé an mheath sa Ghaeilge mar thinneas inti féin.

Teanga agus aigne; aigne agus corp; corp agus sláinte. Ar bhealach, ba shiombal a bhí ina Ghaeilge bhriste den eitinn a chuir isteach ar a shaol leis na blianta. Ba thinneas a bhí ann a chur faoi fhíoreagla é. D'fhéadfaí éalú ó ghalar na drochghaeilge, galar na drochscríbhneoireachta in 
aon teanga, olc go leor agus a bhí siad, ach ba chontúirt nimhneach a bhí san eitinn. Ní gá ach breathnú ar roinnt dá dhánta chun an sceon ina leith a phiocadh suas.

Bhí cumas ag Ó Ríordáin íomhánna a úsáid is a chruthú cé nár úsáid sé a dhóthain iad. Bhí cion ar leith aige ar sholas, mar chomhartha na beatha. B'amhlaidh ansin gur bhain sé leas as moitíf an dorchadais chun bás agus gruaim a chur in iúl.

Is dóigh nach ndéantar é sin a chur os comhair an léitheora aon phioc níos fearr ná sa dán 'An Doircheacht', ina luaitear cé chomh leochaileach is atá an saol daonna ar ocáid nó dhó ag déanamh tagartha do sholas á mhúchadh agus an óiche ag feidhmiú mar chlúdach dheireadh an tsaoil.

'Is daille na hoíche ar mo shúilibh"vi'; 'Gach solas dar las ann do múchadh vii,

Go pointe, bhí Ó Riordáin chomh breoite sin ag tréimhsí áirithe gur fhéach sé ar an mbás mar fhaoiseamh, rud a sciob an eagla a bhain leis an ngalar seo agus an smaoineamh dá shaol a chailliúint.

'Ach tá an doircheacht codlatach séimh, níl cúram ar bith i mo shuillibh viii,

Is éasca téama an bháis agus dearcadh an

Ríordánaigh i leith an saghas saoil a bhí aige. Sa dán 'Claustrophobia', luann sé an bealach go raibh an saol a bhí á chaitheamh aige dá thachtadh de réir a chéile. Mar ghné de seo, luaitear arís an tslí go raibh 'coinneal' á mhúchadh ag 'rialtas na hoíche'. Nascadh na tagairtí seo agus tagairt do Dhia sa dán céanna.

'Tá dealbh mo Thiarna d'réir dealraimh gan chomhacht $t^{i x}$

Go caolchúiseach, is maith an seans go raibh ionannú á dhéanamh aige le bás, tinneas, an saol a bhí aige ag déanamh é a mharú, creideamh ina shaol, Dia b'fhéidir, agus an Eaglais Chaitliceach.

Agus é sin ráite, tá cuid mhaith á léamh as an méid sin ach nuair a dhéanann tú na dánta a chíoradh i gcomhthéacs na gcinn eile, núl sé ró-dheacair na téamaí sin a tharraingt astu.

Tá fianaise ann gur ag lorg freagraí ar a chuid buarthaí is atá O Riordáin an t-am go léir. Taobh thiar den chuardach seo go léir, fanann an cheist shíoraí ina cheann - cá seasann an Dia a d'fhág faoin ngalar eitinn é? Cén fáth go raibh ainsmacht le fulaingt aige ina shaol féin?

Ba léir go bhfuair sé sampla óna mháthair ómós a léiriú do Dhia, ach cár fhág sé sin é? Luaitear cráifeacht na máthar sa dán céanna is a luaitear an easpa tacaíochta a cheap sé a bhí mar chomhartha do Dhia míthrócaireach.
'Tá an tseanbhean fá chritheagla ag féachaint suas trí dhíon an tí, ag lorg Déx

ach

'Tá an doras á chraitheadh is gan Críostaí ann ${ }^{x i}$ ',

Toisc go n-éiríonn leis an dá líne seo a chur isteach i ndán dar teideal 'An Stoirm', tugtar le fios go raibh aincheist ina aigne féin is dócha faoin Dia a bhí á chreidiúint aige. Sampla den nasc idir an tinneas agus an reiligiúin.

Sampla eile ná an dán 'Cnoc Melleri', a thugann an léirmheas is fearr den bhealach gur shíl sé go raibh dlúthbhaint idir an creideamh reiligiúnda go mba cheart dó bheith á chleachtadh agus an bás mall fadálach a mheas sé a bhí ag teacht air.

Arís, feidhmíonn na híomhánna eaglasta go sármhaith. Ba léir go raibh fíorthuiscint aige ar dheasghnátha eaglasta - tagann na tagairtí ar aghaidh go han-soiléir. Bíonn claonadh air ceangal a dhéanamh idir shuíomh a bheadh ina aigne leis an sórt foclóra seo nó leis an gcaidreamh gnéasach nó leis an gcruth baininn.

'Is náir liom aghaidh a thabhairt uirthi, ó tharla sí $i$ bhfear xii,

Ag cur na gcúiseanna sin thuas san áireamh, an bhféadfá a rá gur file faoi sceimhle a bhí ann?

Ní dóigh go bhféadfaí an méid sin a shéanadh. Faoi sceimhle ina aigne féin, aige féin go pearsanta, déarfainn.

Is béag sólás a thug sé dó féin. Rinne sé é féin a chrá ar théama na dea-scríbhneoireachta, leis an ndrochGhaeilge, leis an ndrochsláinte, leis an gcreideamh amhrasach agus leis an easpa caidrimh (pearsanta agus b'fhéidir collaí).

Chiallaigh na nithe sin go léir gur cheap sé nach raibh an mhuinín aige i nDia agus ag pointí faoi leith, mheas sé go raibh bás níos fearr dó nó níos cineálta dó ná maireachtáil sna cúinsí inar mhair sé. Seán Ó Ríordáin - file faoi fhéin sceimhle!

\footnotetext{
i Saoirse; Ll 1, 4-5

ii A Ghaeilge im Pheannsa; Ll 3-4

iii A Ghaeilge im Pheannsa; Ll 26-29

iv A Theanga seo leath-liom; L1 9-10

v A Theanga seo leath-liom; Líne 13

vi An Doircheacht; L 2

vii An Doircheacht; L 6

viii An Doircheacht; Ll 13-14

ix Claustrophobia; Ll 3-4

$\mathrm{x}$ An Stoirm; Ll 7-8

xi An Stoirm; L 1
} 